\title{
Thimerosal: current sources of contact in Brazil
}

\author{
Vanessa Barreto Rocha ${ }^{1}$
}

Maria Antonieta Rios Scherrer ${ }^{1}$

DOI: http://dx.doi.org/10.1590/abd1806-4841.20142645

Abstract: Thimerosal is an organic mercury derivative found in ophthalmic solutions and certain vaccines in Brazil. Although most studies suggest the prevalence of thimerosal sensitivity to be quite high, this condition does not currently have any clinical relevance. The present article surveyed 184 Brazilian products ( 151 topical medications and 33 vaccines) and found that thimerosal was only present in 3 ophthalmic solutions and 5 vaccines.

Keywords: Dermatitis, allergic contact; Dermatitis, Contact; Preservatives, pharmaceutical; Thimerosal

Thimerosal (Merthiolate or Thiomersalate) or sodium ethylmercury salicylate is an organic mercury derivative used as a disinfectant and preservative in contact lens and ophthalmic solutions, vaccines and tattoo inks, the last of which were not investigated in the present article due to a lack of clear information on product labels..$^{1-3}$

Sources of contact and exposure to thimerosal vary according to geographical region. In Brazil, most cases of exposure to thimerosal occurred through the use of Merthiolate, ${ }^{\circledR}$ a common antiseptic which frequently led to acute and intense contact dermatitis. However, in 2001, the National Health Surveillance Agency (ANVISA) forbade the use of mercurials in the production of any pharmaceutical formulations.

Thimerosal is composed of two radicals: an organic mercurial and a thiosalicylate. ${ }^{3}$ Although both components may cause allergic reactions, the proportion of ethylmercury in thimerosal generally acts as the allergic determinant. ${ }^{3}$ Thimerosal sensitivity does not necessarily suggest an allergy to mercury. ${ }^{4}$ Reports of cross-reactions between thimerosal and other mercury components are rare and often confusing, as investigators tend to be unclear as to whether the two radicals were separately tested. ${ }^{3.4}$
Patients who are sensitive to thimerosal may be: negative to other mercurials and thiosalicylic acid, positive to mercurials but negative to thiosalicylic acid, or positive to thiosalicylic acid but negative to other mercurials. ${ }^{3}$

The relationship between allergies to thimerosal and piroxicam is also worth discussing. Piroxicam allergies appear to be more severe in patients who are sensitive to the thiosalicylate content in thimerosal., ${ }^{3,45}$ In these individuals, tenoxicam may be used as an alternative to piroxicam, when necessary. ${ }^{3}$

There appears to be significant geographical variability in the incidence of thimerosal allergies. In Brazil and in the USA, the incidence of individuals with positive contact test results is of 8 to $15 \%$, respectively, while the corresponding rates in Sweden and Denmark are of approximately 3 to $4 \%{ }^{6,7}$ Such differences may be explained by variations in the use and availability of thimerosal-containing products in each country. It is also important to note that, in most countries, contact tests are conducted using vaseline containing $0.1 \%$ thimerosal, while in Brazil, the thimerosal concentration used in these procedures is $0.5 \%{ }^{6}$

Although there is some debate as to whether thimerosal reactions are of an irritative or allergic

Received on 24.03.2013.

Approved by the Advisory Board and accepted for publication on 10.04.2013.

* This study was conducted at the Dermatology Outpatient Clinic of the Clinical Hospital of the Federal University of Minas Gerais (HC-UFMG) - Belo Horizonte (MG), Brazil.

Conflict of interest: None

Financial Support: None

Federal University of Minas Gerais (UFMG) - Belo Horizonte (MG), Brazil.

(C2014 by Anais Brasileiros de Dermatologia 
nature, most of the evidence favors the latter option. ${ }^{3}$

There is also significant controversy regarding the clinical relevance of thimerosal reactions. A study conducted by the North American Contact Dermatitis Group (NACDG) found the prevalence and clinical relevance of thimerosal reactions to be of $10.9 \%$ and $16.8 \%$, respectively, in the 4,087 individuals assessed. ${ }^{8}$ In 2002, the high prevalence of thimerosal reactions in the population led the substance to be named the "allergen of the year" by the American Contact Dermatitis Society. However, the lack of clinical relevance of such reactions prompted Belsito, in the same year, to publish an article declaring thimerosal to be the "non-allergen of the year," and recommending its exclusion from the American skin test battery. ${ }^{6,8} \mathrm{~A}$ Dermatology report released by the Santa Casa of Belo Horizonte found that $14.7 \%$ of the 1,406 patients assessed between 2003 and 2010 tested positive for thimerosal. However, the report did not discuss the clinical relevance of the reactions. ${ }^{6}$

In our service, a total of 381 contact tests using a standard Brazilian battery were conducted between October 2009 and January 2013. A total of $15.8 \%$ of individuals tested positive for thimerosal, but no cases were clinically relevant at the time of assessment. The mean patient age was 44.5 years. None of the seven children aged between 8 and 11 years who were excluded from the study had reacted positively to thimerosal.

Thimerosal allergies may manifest as allergic contact dermatitis or, more rarely, urticaria. The presence of thimerosal in contact lens solutions has also led to a high number of cases of dishydrotic hand eczema in contact lens wearers. However, the real prevalence of thimerosal allergies in these patients is unknown. ${ }^{4}$

The use of thimerosal-containing ocular preparations may also lead to conjunctivitis, which may occur simultaneously with eyelid eczema, as well as corneal infiltration, epithelial punctate keratitis and corneal pseudodendrites. ${ }^{4}$

Although thimerosal is present in hepatitis, tetanus and meningoencephalitis vaccines, significant adverse reactions to these substances are rare. Only $10 \%$ of thimerosal-sensitive patients report adverse reactions to these vaccines. However, these reactions are usually light to moderate, and are often limited to increased pain around the injection site. ${ }^{13,4,5,5,9}$. In 1959, intradermal injections of thimerosal-containing vaccines were reported to cause edema and pruritus in the red areas of tattoos. ${ }^{3}$ However, vaccines are an essential component of disease prevention, and the choice to forego certain vaccines may have a more harmful impact on health than any allergic reactions that may be caused by the procedure. ${ }^{4,5,8}$ In 1997, the Food and Drug Administration (FDA) also emphasized the fact that there is no evidence that the thimerosal content in vaccines caused any adverse reactions save for increased sensitivity around injection sites. ${ }^{10}$

It is possible that contact with the external surface of needles containing thimerosal may increase the allergy risk. To avoid this, Van't Veen and colleagues suggested that individuals should avoid administering vaccines with the same aspiration needle used to remove the content from the flask. ${ }^{4}$

In Brazil, thimerosal is found in a number of ophthalmic products and vaccines. The present authors surveyed the composition of 184 such products by analyzing their labels or contacting the pharmaceutical companies responsible for their production, when necessary. The results of this process can be consulted in chart 1.

Although the prevalence of thimerosal sensitivity may be high, most studies do not mention the age of the affected patients, or the clinical relevance of the allergic reactions detected. There is also a dearth of research into thimerosal sensitivity in pediatric popu-

CHART 1: Thimerosal in pharmaceutical formulations

\begin{tabular}{|c|c|c|}
\hline Products & Number of products researched & Presence of thimerosal/Laboratory \\
\hline Ophthalmic solutions/ & 118 & $3(2.54 \%)$ ophthalmic solutions (Allergan: \\
\hline gels and contact lens solutions & & Cloramphenicol $^{\circledR}$, Fluorescein ${ }^{\circledR}$, Ocufen $^{\circledR}$ ) \\
\hline \multirow[t]{5}{*}{ Vaccines } & 33 & 5 (15.15\%) vaccines: Sanofi-Pasteur: Dyphtheria, \\
\hline & & Mumps, Tetanus, Hepatitis B (Euvax $\left.B^{\circledR}\right)$, \\
\hline & & Influenza (Vaxigrip ${ }^{\circledR}$ ), Poliomyelitis vaccines \\
\hline & & $\left(\right.$ Tetraxim $\left.^{\circledR}\right)$. \\
\hline & & GSK: Influenza Vaccine ${ }^{\circledR}$ \\
\hline Ear-nose-throat products & 33 & Negative \\
\hline
\end{tabular}


lations. Such data would be extremely relevant for assessing the thimerosal exposure of patients who have never had contact with Merthiolate ${ }^{\circledR}$. The present results suggested that, currently, there are few sources of thimerosal sensitization in Brazil, so that the prevalence of prior reactions to thimerosal, which are no longer clinically relevant, is likely to have been caused by previous exposure to the substance. However, further studies are required to confirm this hypothesis.

\section{REFERENCES}

1. Möller H. All these positive tests to thimerosal. Contact Dermatitis. 1994;31:209-13.

2. Leventhal JS, Berger EM, Brauer JA, Cohen DE. Hypersensitivity reactions to vaccine constituents: a case series and review of the literature. Dermatitis. 2012;23:102-9.

3. Rietschel RL, Fowler JF. Fisher's Contact Dermatitis. 6th ed. Hamilton: BC Decker Inc; 2008.

4. van 't Veen AJ, van Joost T. Sensitization to thimerosal (Merthiolate) is still present today. Contact Dermatitis. 1994;31:293-8.

5. Stingeni L, Lapomarda V, Lisi P. What risk of piroxicam photodermatitis in thimerosal positive patients? Contact Dermatitis. 1996;34:60-1.

6. Rodrigues DR, Neves DR, Pinto JM, Alves MFF, Fulgêncio ACF. Results of patchtests from Santa Casa de Belo Horizonte Dermatology Clinic, Belo Horizonte, Brazil, from 2003 to 2010. An Bras Dermatol. 2012;87:800-3.

7. Moriearty PL, Pereira C, Guimarães NA. Contact Dermatitis in Salvador, Brazil. Contact Dermatitis. 1978;4:185-9.

8. Belsito DV. Thimerosal: contact (non)allergen of the year. Am J Contact Dermat. 2002;13:1-2.

9. Breithaupt $A$, Jacob SE. Thimerosal and the relevance of patch test reactions in children. Dermatitis. 2008;19:275-7.

10. King K, Paterson M, Green SK. Global justice and the proposed ban on thimerosal containing vaccines. Pediatrics. 2013;131:154-6.

\section{MAILING ADDRESS: \\ Vanessa Barreto Rocha \\ Av. Contorno, 9681 sl 403 - Prado \\ 30.110-063 - Belo Horizonte - MG \\ Brazil \\ E-mail:vanessabarreto@oi.com.br}

How to cite this article: Rocha VB, Scherrer MAR Thimerosal: current sources of contact in Brazil. An Bras Dermatol. 2014;89(2):376-8. 